\title{
Cancer-associated fibroblasts promote the progression of endometrial cancer via the SDF-1/CXCR4 axis
}

Fei Teng ${ }^{\dagger}$, Wen-Yan Tian ${ }^{\dagger}$, Ying-Mei Wang ${ }^{*}$, Yan-Fang Zhang, Fei Guo, Jing Zhao, Chao Gao and Feng-Xia Xue

\begin{abstract}
Background: Cancer-associated fibroblasts (CAFs) are believed to play an essential role in cancer initiation and development. However, little research has been undertaken to evaluate the role of CAFs in endometrial cancer (EC) progression. We aim to detect the functional contributions of CAFs to promote progression of EC.

Methods: Stromal fibroblasts were isolated from endometrioid adenocarcinomas and normal endometrial tissues. The conditioned media of cultured CAFs and normal fibroblasts (NFs) were collected to detect the level of stromal cell-derived factor-1alpha (SDF-1a), macrophage chemoattractant protein-1 (MCP-1), migration inhibitory factor (MIF), colony stimulating factor-1 (CSF-1), and interleukin-1 (IL-1) by ELISA. The CAFs or NFs were cocultured with EC cell lines to determine the proliferation, migration, and invasion by MTT assays and transwell chambers. Xenograft models were used to observe tumor growth. Matrix metalloproteinases (MMP)-2 and MMP-9 activity was evaluated by zymography. AMD3100 (a chemokine receptor 4 (CXCR4) antagonist) was used to block the SDF-1/CXCR4 axis. Neutralizing antibodies were used to detect PI3K/Akt and MAPK/Erk pathways by western blotting. SDF-1a and CXCR4 expressions were analyzed in xenotransplanted tumors and 348 cases by immunohistochemistry.
\end{abstract}

Results: CAFs promoted proliferation, migration, and invasion as well as in vivo tumorigenesis of admixed EC cells significantly more than NFs by secreting SDF-1a. These effects were significantly inhibited by AMD3100. CAFs promoted EC progression via the SDF-1a/CXCR4 axis to activate the PI3K/Akt and MAPK/Erk signalings in a paracrine-dependent manner or increase MMP-2 and MMP-9 secretion in an autocrine-dependent manner. SDF-1a and CXCR4 expression upregulation accompanied clinical EC development and progression. High SDF-1a expression levels were associated with deep myometrial invasion, lymph node metastasis, and poor prognosis in EC.

Conclusions: Our data indicated that CAFs derived from EC tissues promoted EC progression via the SDF-1/CXCR4 axis in a paracrine- or autocrine-dependent manner. SDF-1a is a novel independent poor prognostic factor for EC patients' survival. Targeting the SDF-1/CXCR4 axis might provide a novel therapeutic strategy for EC treatment.

Keywords: Tumor microenvironment, Cancer-associated fibroblasts, Endometrial cancer, Stromal cell-derived factor-1a, CXCR4, Prognosis

\footnotetext{
* Correspondence: yingmeiwang@gmail.com; fengxiaxue1962@gmail.com

${ }^{\dagger}$ Equal contributors

Department of Gynecology and Obstetrics, Tianjin Medical University General

Hospital, NO 154, Anshan Road, He Ping District, Tianjin 300052, China
} 


\section{Background}

Endometrial cancer (EC) is the most common gynecological malignancy in developed countries, with approximately 52,630 new cases and 8590 deaths occurring in the USA in 2014 [1]. With changes in Western lifestyles and the rising prevalence of obesity in developing countries, the incidence of EC has increased at a surprisingly rapid rate in China [2]. For patients with advanced or recurrent disease or for those who wish to preserve their fertility, the treatment options are limited. Therefore, it is of great urgency to understand the mechanisms of EC so that specific therapeutic targets can be designed and developed.

Solid tumors, including EC, consist of tumor cells and various types of stromal cells; thus, tumor progression is determined not only by the tumor cells themselves but also by the tumor stroma. Previous studies have shown that the crosstalk between tumor cells and their surrounding stroma plays an important role in tumor development [3, 4]. Myofibroblasts in the tumor stroma, collectively called cancer-associated fibroblasts (CAFs), are large, spindle-shaped mesenchymal cells that share characteristics with smooth muscle cells that expressed both vimentin and alpha-smooth muscle actin ( $\alpha$-SMA) [5]. CAFs also exhibit similar phenotypes with mesenchymal stem cells; both cell types secrete similar cytokines [6], while mesenchymal stem cells could produce large amounts of exosomes [7]. The presence of CAFs was proposed to precede tumor cell initiation, proliferation, invasion metastasis, angiogenesis, and chemoresistance in vitro experiments in prostate cancer, pancreatic cancer, gastric cancer, and breast cancer [8-12]. However, the mechanisms linking CAFs and cancer progression are not fully understood.

CAFs can secrete variety of factors, such as cytokines, chemokines, and growth factors. These soluble factors are involved in paracrine signaling or in autocrine loops to contribute to tumor progression [13], stromal cellderived factor-1alpha (SDF-1 $\alpha)($ CXCL12) is a member of the CXC chemokine family, the chemotactic effects of which are mediated by interaction with chemokine receptor 4 (CXCR4). Typically, SDF-1, which is expressed in the stromal fibroblasts of some organs, including the brain, breasts, liver, lungs, and lymph nodes, is involved in carcinoma survival, proliferation, and metastasis [14-16]. Malgorzata et al. found that increased expression of SDF-1 was correlated with a more aggressive phenotype and a negative prognostic factor of EC [17]. In addition, previous studies showed that CAFs secrete SDF-1, activate SDF-1/CXCR4 axis, and promote tumor progression [18, 19]. Other researchers have also showed that blocking the interaction between SDF-1 and CXCR4 could inhibit the number or size of tumor metastases [20-23]. Therefore, we investigated whether CAFs played a role in promoting the progression of EC by secreting SDF-1.

To test this hypothesis, we established several primary cultures of CAFs and normal fibroblasts (NFs) from EC tissues and normal endometrial tissues, and then, we cocultured CAFs or NFs with EC cell lines in vivo and in vitro. We concluded that, in contrast to NFs, CAFs promoted EC cell proliferation, migration, and invasion. We measured the levels of SDF-1 $\alpha$ in the conditioned media harvested from NFs and CAFs. We found that CAF-mediated EC progression was modulated via the SDF-1/CXCR4 axis, which activated intracellular PI3K/ Akt and/or MAPK/Erk signalings and increased active matrix metalloproteinases (MMP)-2 and MMP-9 expressions. Furthermore, we determined SDF-1 $\alpha$ and CXCR4 expression levels and their relationships with clinicopathologic features and clinical outcomes in human EC patients. This study provides new evidence elucidating the pro-tumorigenic role of CAFs in the progression of EC.

\section{Results \\ Establishment of primary fibroblast cells}

To establish primary fibroblast cells, normal endometrial tissues or EC tissues were digested with collagenase and hyaluronidase. The primary fibroblast cells displayed elongated spindle-shaped features. The fibroblast cells were verified using anti-vimentin, anti- $\alpha$-SMA, anti-fibroblastactivating protein (FAP), and anti-fibroblast-specific protein (FSP)-1 antibodies. The antibody to CD31 was used to demonstrate a lack of endothelial cell contamination, while cytokeratin (CK) was used to exclude epithelial components. CAFs isolated from EC tissues were negative for CK and CD31 expression, moderately positive for vimentin expression, but highly positive for $\alpha$-SMA, FSP-1, and FAP expression. NFs isolated from normal endometrial tissues showed negative expression of CK and CD31 and moderate expression of vimentin, $\alpha$ SMA, FSP-1, and FAP. These findings are indicating that the isolated fibroblast cells were relatively pure and free of epithelial cells or endothelial cells contamination (Fig. 1a).

\section{CAFs promoted EC cell growth and tumorigenesis}

To investigate whether CAFs play an important role in the progression of EC, we conducted MTT assays to evaluate the proliferation of EC cell lines cocultured with CAFs or NFs for 4 days. Both CAFs and NFs promoted the proliferation of HEC-1B and ECC-1 cells in a timedependent manner. CAFs, compared with NFs, had more prominent potential to promote HEC-1B and ECC-1 cell proliferation at $72 \mathrm{~h}(P<0.05$; Fig. $1 \mathrm{~b}, \mathrm{c})$.

Next, to evaluate the contribution of CAFs to tumor growth in vivo, we developed a human tumor xenograft model that has both stromal and epithelial compartments 


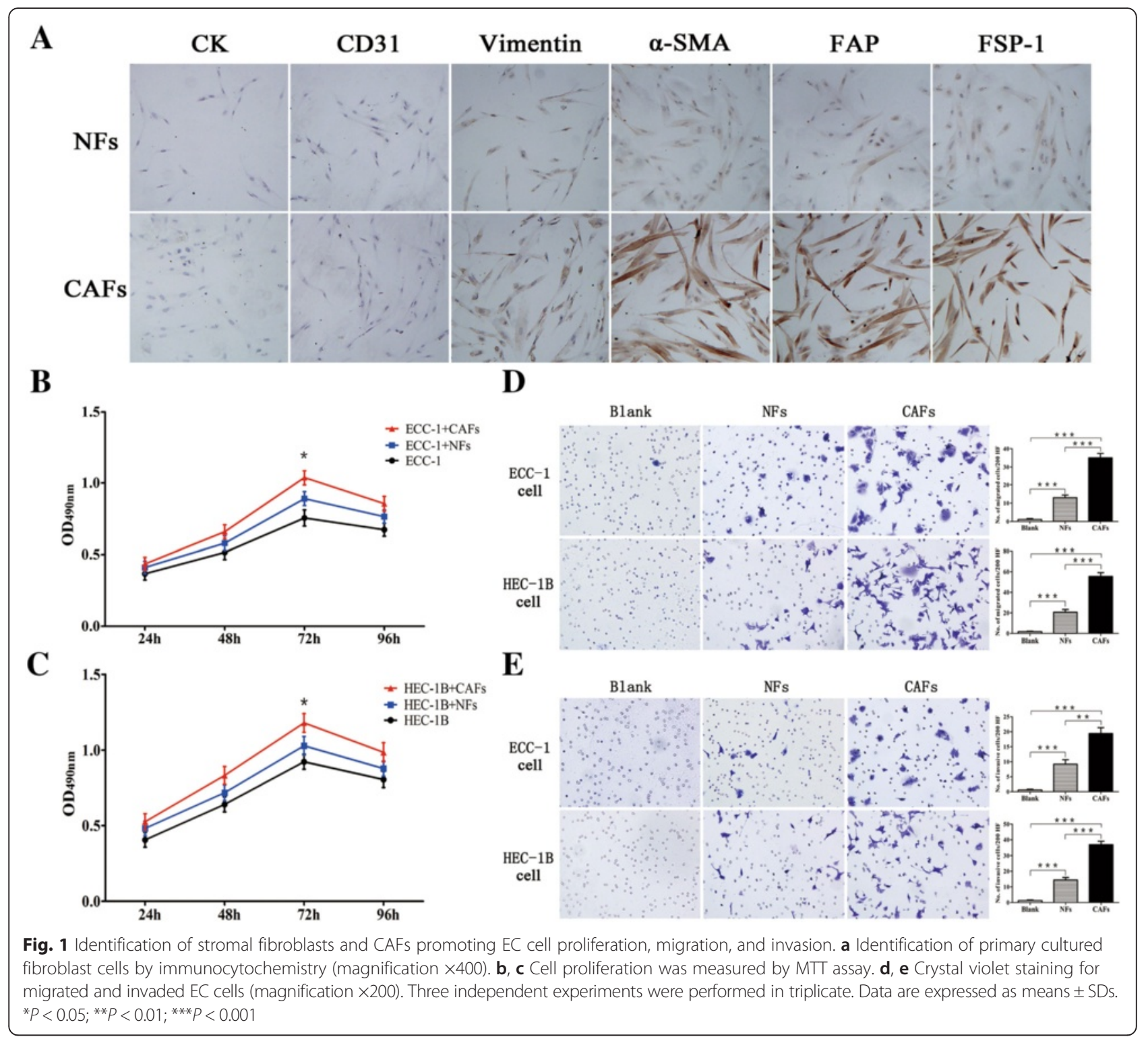

in the engrafted tumors. We mixed CAFs or NFs with HEC-1B cells at a 3:1 ratio and inoculated these mixtures subcutaneously into the right flanks of immunodeficient nude mice. The tumor formation was monitored. HEC-1B cells co-mixed with CAFs generated tumors of greater volume and weight than HEC-1B cells mixed with NFs or HEC-1B cells alone (Fig. $2 \mathrm{a}-\mathrm{d}$ ). The stromal fibroblasts' phenotypes were determined by immunohistochemistry using antibodies specific for human CK, vimentin, $\alpha$-SMA, FAP, and FSP-1. The CAFs were negative for CK expression and weakly positive for vimentin and $\alpha$-SMA expression but moderately positive for FSP- 1 and FAP expression. The NFs showed negative expression of $\mathrm{CK}$ and weak expression of vimentin, $\alpha$-SMA, FSP-1, and FAP (Fig. 2e). These results suggested that the human originated CAFs promoted the growth and tumorigenesis of EC.

\section{CAFs promoted EC cells migration and invasion}

A coculture method was used to determine whether CAFs secreted factors that could stimulate the migration and invasion of EC cells in vitro. Our findings showed that the number of migrating ECC-1 cells increased by coculturing with CAFs, compared to coculturing with NFs or control medium $(P<0.001$; Fig. $1 d)$. Invasion followed the same pattern with migration; the number of invading cells was significantly greater for coculturing with CAFs, compared to coculturing with NFs or control medium $(P<0.001$; Fig. 1e). Consistent results were obtained with HEC-1B cells (Fig. 1d, e). 


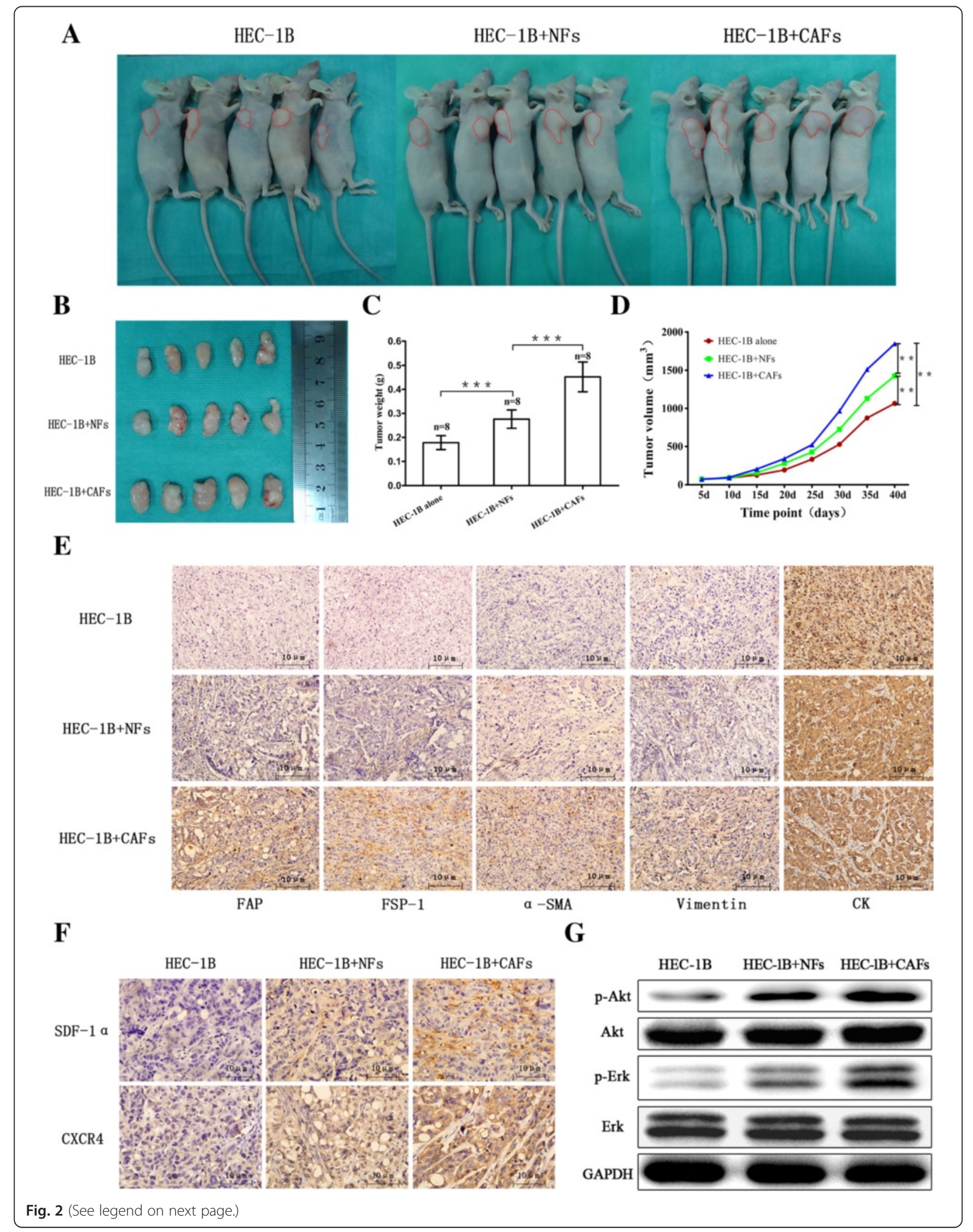


(See figure on previous page.)

Fig. 2 CAFs comingled with HEC-1B cells, enhancing xenograft growth in nude mice. $\mathbf{a}$, b Gross appearance of xenografts; HEC-1B cells were injected alone or were coinjected with various fibroblasts subcutaneously into the right flanks of 4-week-old nude mice, and xenografts were harvested after 40 days of growth in female hosts. c Average tumor weight in each group was evaluated at 40 days after injection. Error bars depict the standard error around the mean. ${ }^{* *} P<0.001$. d Tumor volume was plotted on the indicated days. ${ }^{* *} P<0.01$; ${ }^{* *} P<0.001$. e Sections of xenografts in different groups were submitted to immunohistochemistry using antibodies specific for human CK, vimentin, a-SMA, FAP, and FSP-1. Scale bar, 10 m. $\mathbf{f}$ Expression of SDF-1a and CXCR4 in xenotransplanted tumors. $\mathbf{g}$ Western blot analysis detection of the phosphorylation of Ark and Erk protein expression in xenotransplanted tumors

\section{Cytokines were secreted by NFs/CAFs in the culture supernatant}

To determine the factors responsible for CAF-mediated cell proliferation, migration, and invasion, we measured the levels of SDF-1 $\alpha$, macrophage chemoattractant protein-1 (MCP-1), migration inhibitory factor (MIF), colony stimulating factor-1 (CSF-1), and interleukin-1 (IL-1) in the conditioned media harvested from ECC-1 cells, HEC-1B cells, NFs, and CAFs. CAFs secreted greater amount of SDF-1 $\alpha, \mathrm{MCP}-1$, and MIF when compared to NFs and EC cells. Of this class of cytokines, a significant higher level of SDF-1 $\alpha$ than MCP-1 (approximately threefold) and MIF (approximately threefold) levels were secreted by CAFs (Fig. 3a). Therefore, we focused on the SDF- $1 \alpha$ and tested the protein concentration in the conditioned media of EC cells, NFs, and CAFs for 24, 48, 72, and $96 \mathrm{~h}$. This assay indicated that SDF- $1 \alpha$ in the conditioned media from CAFs was significantly higher than that from NFs or EC cell lines (Fig. 3b).

\section{A crucial role for the SDF-1/CXCR4 axis in the promotion of EC progression}

Finally, to determine whether SDF- $1 \alpha$ secreted by CAFs was closely involved in the proliferation, migration, and invasion of EC cells, we treated EC cells with AMD3100 (a CXCR4 antagonist) in presence of CAF-conditioned media in vitro. SDF-1 $\alpha$-induced cell proliferation, migration, and invasion were significantly inhibited by AMD3100 pretreatment (Fig. 3c, e, f).

\section{MMP-2 and MMP-9 activity was regulated by the SDF-1/} CXCR4 axis in an autocrine-dependent manner in CAFs

CAFs could dramatically increase the mobility of EC cells and their invasion through Matrigel. These effects of CAFs did not require direct cell-cell contact because the conditioned media of CAFs produced essentially the same effects. Correlated with this finding, conditioned media from HEC-1B cells, NFs, and CAFs were analyzed by zymography. Compared with conditioned media from with NFs or HEC-1B cells, conditioned media from CAFs resulted in increased MMP-2 and MMP-9 gelatinase activity. When CAFs were treated with AMD3100, MMP-2 and MMP-9 expression was reduced (Fig. 3d). These findings indicated that CAFs mediated the invasion and metastasis of $\mathrm{EC}$ via the SDF-1/CXCR4 axis in an autocrine-dependent mode.

\section{Activation of the PI3K/Akt and MAPK/Erk signalings in CAF-mediated EC cells proliferation}

To elucidate the mechanisms underlying the growthpromoting effects of CAF secretion on EC, we determined the activation of PI3K/Akt and MAPK/Erk, two major signalings implicated in EC. HEC-1B cells were starved in serum-free medium for $12 \mathrm{~h}$ and incubated with DMEM/F12, the condition media of NFs and CAFs and CXCR4 antagonists (AMD3100 200 ng/ml, 500 ng/ $\mathrm{ml}$ ). HEC-1B cells were pretreated with AMD3100 for $1 \mathrm{~h}$ and incubated with the condition media of CAFs for $30 \mathrm{~min}$. Phospho-Akt and phospho-Erk $1 / 2$ protein levels were elevated when HEC-1B cells were treated with CAFs supernatant compared with NFs supernatant. Next, CXCR4 was blocked by its antagonist, and the phosphorylation of Akt and Erk 1/2 in response to SDF$1 \alpha$ was significantly decreased (Fig. $3 g$ ). In addition, we observed that the elevated phosphorylation of Akt and Erk $1 / 2$ protein levels in the xenografts tumors containing CAFs compared to tumors without fibroblasts or containing NFs (Fig. 2g). These data suggested that the activation status of the PI3K/Akt and/or MAPK/Erk signalings might be the key point in CAF-mediated EC cells proliferation.

\section{Expression of SDF-1a in EC}

To determine SDF-1 $\alpha$ 's role in EC tumorigenesis and progression, we performed immunohistochemical analysis to evaluate SDF- $1 \alpha$ expression in xenotransplanted tumors, as well as in normal endometrium (NE), hyperplastic endometrium (HE), atypical hyperplastic endometrium (AHE), and EC tissue microarrays. SDF- $1 \alpha$ staining intensity was greater in the stromal compartment than in the endometrial epithelial compartment, and its staining was located in the membrane and/or cytoplasm. SDF- $1 \alpha$ expression was stronger in the xenografts tumor containing CAFs compared to tumors without fibroblasts or containing NFs (Fig. 2f). Among the 348 cases available for analysis, SDF-1 $\alpha$ expression was lowest in NE tissues; the levels were higher in $\mathrm{HE}$ 


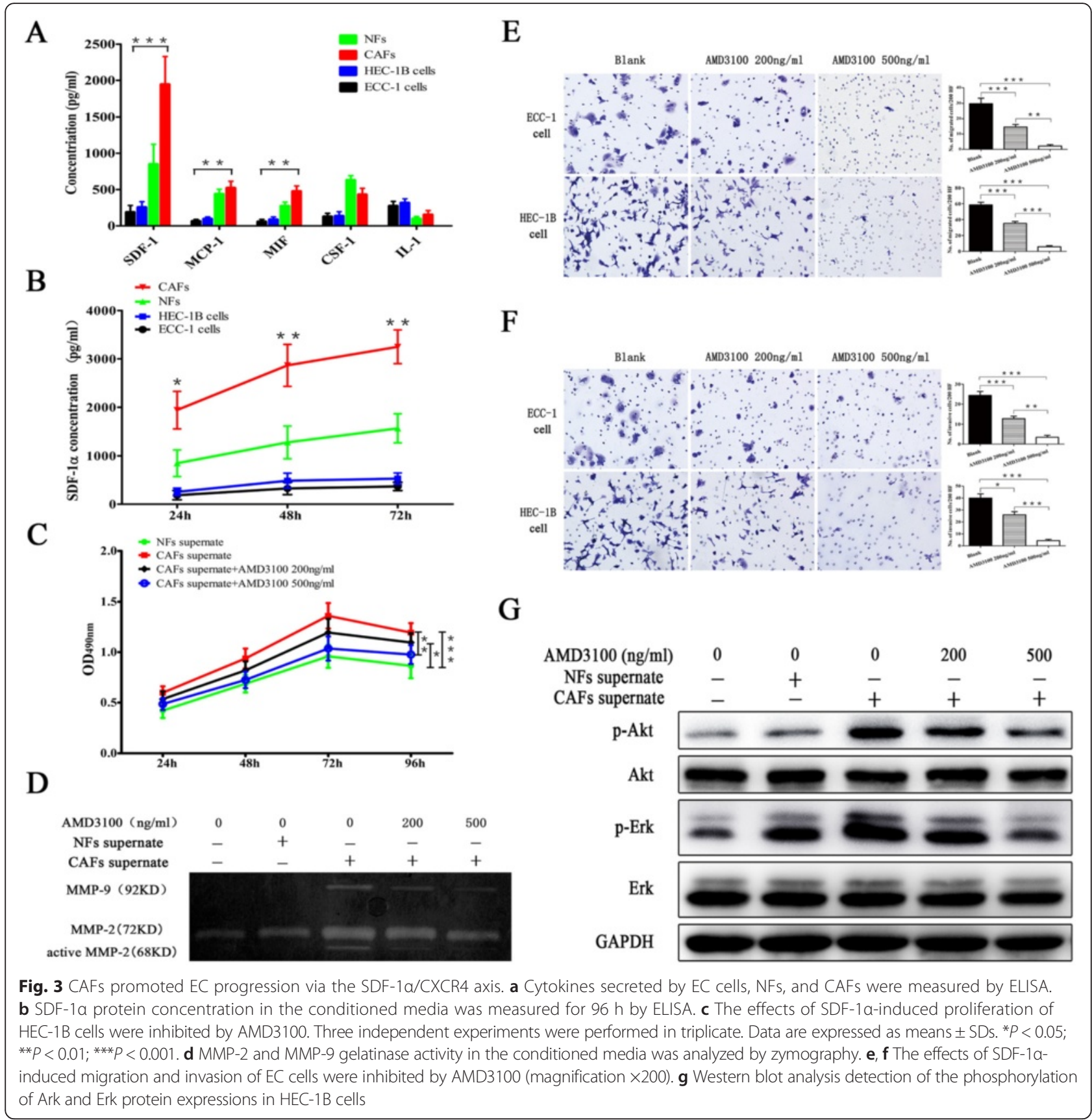

and AHE tissues and highest in EC tissues $\left(\chi^{2}=86.826\right.$, $P=0.000$; Fig. 4a). More specifically, SDF- $1 \alpha$ expression was significantly higher in EC tissues than in NE tissues $(P=0.000)$, in HE tissues $(P=0.000)$, and in AHE tissues $(P=0.000)$. There were significant differences in tissue SDF-1 $\alpha$ expression between AHE and HE tissues $(P=0.000)$, whereas there were no significant differences in tissue SDF- $1 \alpha$ expression between AHE and NE tissues $(P=0.233)$ or between HE and NE tissues $(P=0.923)$.

\section{Correlations between SDF-1a expression and clinicopathologic factors}

We next analyzed the correlations between SDF- $1 \alpha$ expression and various clinicopathologic factors that could affect the prognosis of patients with EC. Statistical analysis revealed that SDF- $1 \alpha$ expression was significantly increased during the NE-HE-AHE-EC sequence in the 348 samples. The analyses revealed that, among the 202 EC patients, a high level of SDF- $1 \alpha$ expression was associated with lymph node metastasis 


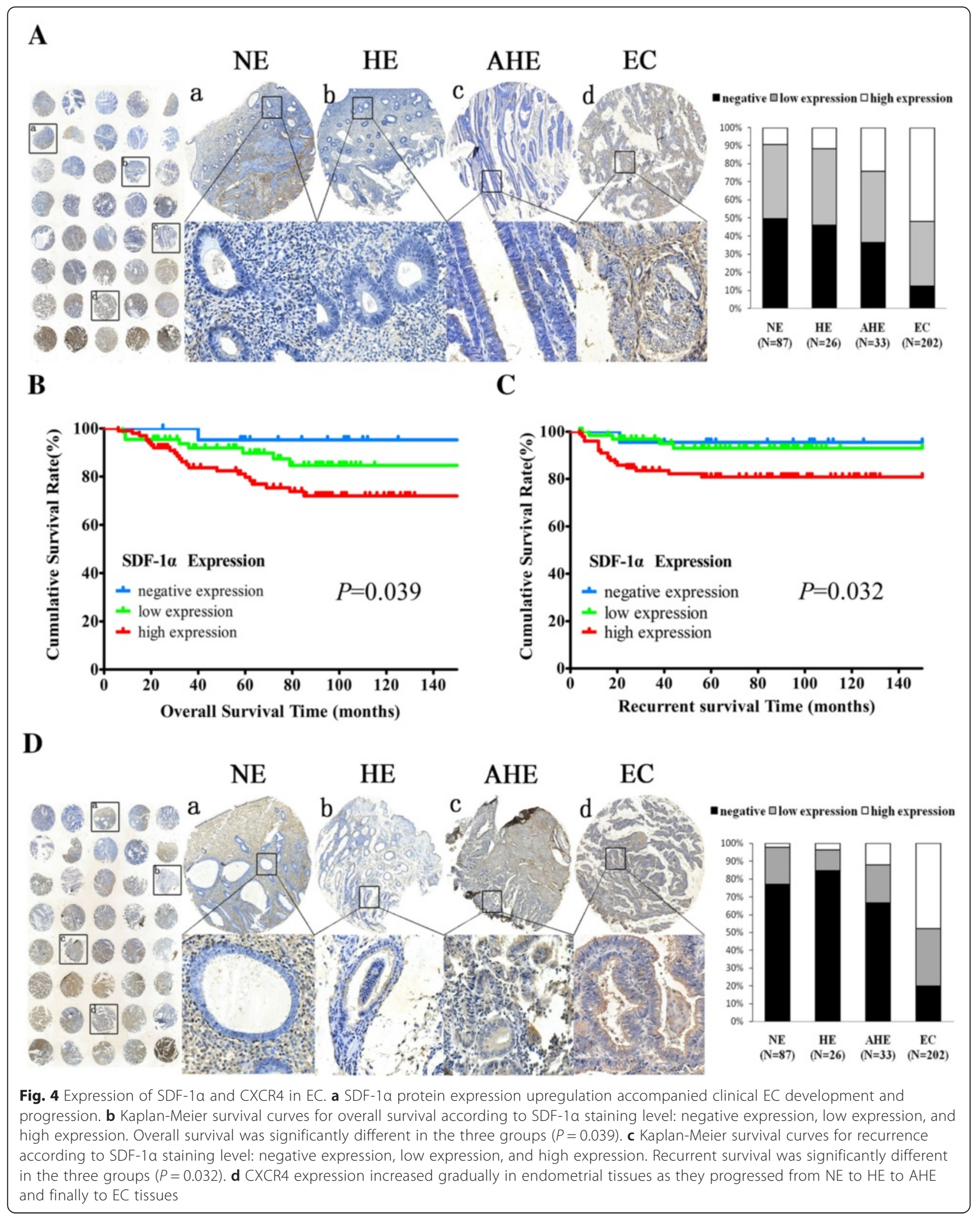


$(P=0.038)$ and deep myometrial invasion (myometrial invasion $\geq 1 / 2 ; P=0.018)$. In contrast, SDF- $1 \alpha$ expression was not correlated with age at diagnosis, menopausal status, histologic subtype, histopathologic grade, or advanced tumor stage (Table 1).

\section{Correlation between SDF-1a expression and survival}

To investigate further the clinical relevance of SDF- $1 \alpha$ expression in EC, we compared overall survival according to SDF- $1 \alpha$ expression using Kaplan-Meier estimates. A total of 15 patients were lost to follow-up; thus, the data from 187 patients were included in the analysis. Of the $32(17.11 \%)$ patients who died, 21 (65.62 \%) died of cancer and 11 (34.38\%) died of other causes, namely heart failure, cerebral infarction, chronic diseases, and cerebral hemorrhage. Remarkably, regarding the 10-year survival rates in the negative SDF- $1 \alpha$ expression group, $21(95.45 \%)$ patients survived, and 1 patient (4.55\%) died. In the low SDF-1 $\alpha$ expression group, 57 (87.69 \%) patients survived, and 8 patients (12.31\%) died. Finally, in the high SDF-1 $\alpha$ expression group, 77 (77.00 \%) patients survived, and 23 patients $(23.00 \%)$ died. These data suggested a better prognosis for the negative SDF$1 \alpha$ expression group than for the low expression and high expression groups $\left(\chi^{2}=6.473, P=0.039\right.$; Fig. $\left.4 b\right)$. Moreover, we also compared the correlation between SDF- $1 \alpha$ expression and recurrent survival. Recurrence occurred in 23 of the 187 EC patients. In the negative SDF- $1 \alpha$ expression group, $1(4.55 \%)$ recurred. In the low SDF-1 $\alpha$ expression group, 4 (6.15 \%) recurred. In the high SDF-1 $\alpha$ expression group, 18 (18.00\%) recurred. These data illustrated a lower trend of recurrence for the negative expression group than for the low expression and high expression groups $\left(\chi^{2}=6.891\right.$, $P=0.032$; Fig. 4c).

To evaluate the prognostic factors related to EC patients' survival, hazard ratios (HRs) were estimated using multivariate Cox regression analysis as shown in Table 2. After adjusting for age at diagnosis, menopausal status, tumor histopathologic grade, histopathologic subtype, International Federation of Gynecology and Obstetrics (FIGO) stage, and lymph node metastasis, we found that

Table 1 Associations between tissue SDF-1a expression and clinicopathologic characteristics of EC patients

\begin{tabular}{|c|c|c|c|c|c|c|}
\hline \multirow[t]{2}{*}{ Variables } & \multicolumn{3}{|c|}{ SDF-1a expression (n (\%)) } & \multirow{2}{*}{$\begin{array}{c}\text { Total } \\
N\end{array}$} & \multirow[t]{2}{*}{$x^{2}$} & \multirow[t]{2}{*}{$P$} \\
\hline & Negative & Low & High & & & \\
\hline \multicolumn{7}{|c|}{ Age at diagnosis (years) } \\
\hline$<60$ & $14(11.2)$ & $43(34.4)$ & $68(54.4)$ & 125 & \multirow[t]{2}{*}{1.133} & \multirow[t]{2}{*}{0.567} \\
\hline$\geq 60$ & $12(15.6)$ & $28(36.4)$ & $37(48.0)$ & 77 & & \\
\hline \multicolumn{7}{|l|}{ Menopausal status } \\
\hline Yes & $15(10.6)$ & $53(37.6)$ & $73(51.8)$ & 141 & \multirow[t]{2}{*}{2.604} & \multirow[t]{2}{*}{0.272} \\
\hline No & $11(18.0)$ & $18(29.5)$ & $32(52.5)$ & 61 & & \\
\hline \multicolumn{7}{|l|}{ Histologic subtype } \\
\hline Endometrioid & $22(11.9)$ & $66(35.7)$ & $97(52.4)$ & 185 & \multirow[t]{2}{*}{1.616} & \multirow[t]{2}{*}{0.446} \\
\hline Nonendometrioid & $4(23.5)$ & $5(29.4)$ & $8(47.1)$ & 17 & & \\
\hline \multicolumn{7}{|l|}{ Histopathologic grade } \\
\hline G1 & $14(14.4)$ & $34(35.1)$ & $49(50.5)$ & 97 & \multirow[t]{3}{*}{1.460} & \multirow[t]{3}{*}{0.834} \\
\hline $\mathrm{G} 2$ & $7(9.2)$ & $29(38.2)$ & $40(52.6)$ & 76 & & \\
\hline G3 & $4(13.8)$ & $9(31.0)$ & $16(55.2)$ & 29 & & \\
\hline \multicolumn{7}{|l|}{ Myometrial invasion } \\
\hline$<1 / 2$ & $16(10.9)$ & $60(40.8)$ & $71(48.3)$ & 147 & \multirow[t]{2}{*}{7.998} & \multirow[t]{2}{*}{$0.018^{*}$} \\
\hline$\geq 1 / 2$ & $10(18.2)$ & $11(20.0)$ & $34(61.8)$ & 55 & & \\
\hline \multicolumn{7}{|l|}{ FIGO stage } \\
\hline$|-| \mid$ & $22(13.2)$ & $63(37.7)$ & $82(49.1)$ & 167 & \multirow[t]{2}{*}{3.456} & \multirow[t]{2}{*}{0.172} \\
\hline III-IV & $4(11.4)$ & $8(22.9)$ & $23(65.7)$ & 35 & & \\
\hline \multicolumn{7}{|c|}{ Lymph node metastasis } \\
\hline Yes & $1(6.3)$ & $2(12.5)$ & $13(81.2)$ & 16 & \multirow[t]{2}{*}{6.530} & \multirow[t]{2}{*}{$0.038^{*}$} \\
\hline No & 24 (12.9) & 70 (37.6) & $92(49.5)$ & 186 & & \\
\hline
\end{tabular}

The data are presented as numbers of cases (percentages of cases)

* indicates $P<0.05$ 
Table 2 Multivariate analysis of factors associated with survival of EC patients

\begin{tabular}{|c|c|c|c|c|c|}
\hline Variables & & $H R$ & $95 \% \mathrm{Cl}$ & Wald value & $P$ \\
\hline \multirow[t]{2}{*}{ Age (years) } & $<60$ & 1.00 & $0.55-3.43$ & 0.45 & 0.501 \\
\hline & $\geq 60$ & 1.37 & & & \\
\hline \multirow[t]{2}{*}{ Menopausal status } & Yes & 1.00 & $0.18-1.90$ & 0.83 & 0.363 \\
\hline & No & 0.58 & & & \\
\hline \multirow[t]{2}{*}{ Histologic subtype } & Endometrioid & 1.00 & $0.67-7.82$ & 1.74 & 0.187 \\
\hline & Nonendometrioid & 2.29 & & & \\
\hline \multirow[t]{2}{*}{ Histopathologic grade } & G1 & 1.00 & $0.55-2.97$ & 0.31 & 0.578 \\
\hline & G2-G3 & 1.27 & & & \\
\hline \multirow[t]{2}{*}{ Myometrial invasion } & $<1 / 2$ & 1.00 & $1.08-7.09$ & 4.50 & $0.034^{*}$ \\
\hline & $\geq 1 / 2$ & 2.77 & & & \\
\hline \multirow[t]{2}{*}{ FIGO stage } & $|-| \mid$ & 1.00 & $0.43-3.99$ & 0.22 & 0.639 \\
\hline & III-IV & 1.31 & & & \\
\hline \multirow[t]{2}{*}{ Lymph node metastasis } & Yes & 1.00 & $0.22-2.27$ & 0.335 & 0.563 \\
\hline & No & 0.71 & & & \\
\hline \multirow[t]{2}{*}{ SDF-1a expression } & Low expression & 1.00 & $1.58-11.07$ & 7.918 & $0.005^{*}$ \\
\hline & High expression & 4.13 & & & \\
\hline
\end{tabular}

${ }^{* P}<0.05$

high expression of SDF-1 $\alpha$ (HR, 4.13; $95 \%$ confidence interval (CI), $1.58-11.07 ; P=0.005)$ and deep myometrial invasion (HR, 2.77; $95 \% \mathrm{CI}, 1.08-7.09 ; P=0.034$ ) were independent factors predicting cancer-specific survival in EC patients (Table 2). Altogether, our findings indicated that SDF- $1 \alpha$ expression might be a useful marker for predicting the survival of patients with EC.

\section{Expression of CXCR4 in EC}

Furthermore, we investigated CXCR4 expression in xenotransplanted tumors, as well as in NE, HE, AHE, and EC tissue microarrays. CXCR4 immunostaining was more intense in the endometrial epithelium than in the stroma, and its staining was located in the membrane. CXCR4 expression was stronger in the xenograft tumor containing CAFs compared to tumors without fibroblasts or containing NFs (Fig. 2f) and increased gradually in endometrial tissues as they progressed from NE to HE to AHE and finally to EC tissues $\left(\chi^{2}=\right.$ 139.485, $P=0.000$; Fig. 4d). Additionally, CXCR4 expression was higher in EC tissues than in NE tissues $(P=0.000)$, in HE tissues $(P=0.000)$ and in AHE tissues $(P=0.000)$, whereas there were no differences between AHE and HE tissues $(P=0.111)$, between AHE and NE tissues $(P=0.172)$, or between $\mathrm{HE}$ and NE tissues $(P=0.443)$.

We also determined that CXCR4 expression in EC tissues was not correlated with any prognostic factors. Finally, we found that there was no association between CXCR4 expression in EC tissues and overall survival.

\section{Discussion}

Myofibroblast-rich cell populations, originally introduced as CAFs, represent one of the most abundant stromal cell types in various type of cancer, including EC. Different cellular origins and tumor-derived factors affect the phenotype of CAFs and contribute to their appearance as heterogeneous cell populations with distinct subtypes [13]. Some studies have reported a role of promoter in tumor growth and progression [24-28]; however, recent data obtained from in vitro cocultures and in vivo xenograft models have shown a tumor-inhibitory role of CAFs [29-32]. It remains unknown whether CAFs in EC exhibit pro-malignant properties or antimalignant characteristics. To clarify this role, CAF cell population and NF cell population were established from human EC tissues and normal endometrial tissues. The present study revealed that CAFs in EC were different from the NFs in several important functional respects. (1) CAFs were more competent than the NFs in enhancing tumor growth, migration, and invasion by comingling with EC cells in in vivo and in vitro experiments. (2) CAFs produced increased level of SDF-1 $\alpha$ and (3) CAFs promoted EC cells progression via the SDF-1/ CXCR4 axis in a paracrine-/autocrine-dependent manners. (4) SDF-1 $\alpha$ expression was upregulated and was associated with EC progression and poor prognosis, while the increased expression of CXCR4 in EC tissues was not correlated with any prognostic factors.

As we know, few studies have used CAFs from human EC samples due to the relative paucity of available fresh tumor specimens and the limited life span of primary 
cells [33]. CAFs or NFs grow slowly and eventually senesce after 10 to 15 passages; therefore, all of the primary cells in our study were obtained at earlier than 10 passages, to maintain the closest phenotype to the primary tissues. Our data showed that CAFs, distinctly differently from NFs, exhibited a pro-tumorigenic effect by coculture with EC cells. Similar to Olumi's finding [5], human prostatic CAFs grown with initiated human prostatic epithelial cells dramatically stimulated growth and altered histology of the epithelial population. This effect was not detected when NFs grown with initiated human prostatic epithelial cells under identical conditions. Furthermore, studies have demonstrated that stromal cells isolated from proliferative NE are capable of suppressing the growth of the EC cell line (Ishikawa), even in response to estrogen $[34,35]$. Such effects were specific to the fibroblasts derived from normal endometrium because fibroblasts from normal foreskin failed to exhibit similar effects [34]. Thus, different fibroblasts subtypes display different phenotypes. However, it is less clear whether fibroblast subpopulations stimulate distinct aspects during different stages of malignancy.

CAFs can promote tumor growth, angiogenesis, and metastasis through communication with cancer cells, such as by secreting various important factors in paracrine- or autocrine-dependent manners. Among these factors, SDF-1 has sparked substantial interest because of its pro-tumorigenic role. SDF-1 has two major isoforms, $\alpha$ and $\beta$. Both are derived from a single gene, due to alternative splicing. SDF-1 $\alpha$ is the predominant isoform, and it is secreted by stromal cells and is found nearly in all the organs [36]. The chemokine SDF-1 is an important $\alpha$-chemokine that binds to its cognate receptor CXCR4 and regulates the trafficking of normal and malignant cells [37]. Thus, we chose the SDF- $1 \alpha$ as a target in this research. We demonstrated that SDF- $1 \alpha$ released by CAFs induced cell proliferation, mobility, and invasiveness in EC cells. At the same time, AMD3100, a synthetic antagonist known to block CXCR4 function [38], could significantly suppress these effects, consistent with its action in other malignancies [20,39].

Schmidt et al. have observed that SDF-1 $\alpha$ induced the development of EC cells in vitro [40]. However, to date, activation of the intracellular signal transduction induced by SDF-1 $\alpha$ in EC has been seldom reported. Tsukamoto and colleagues demonstrated that SDF-1 $\alpha$ mediated the activation of the PI3K/Akt pathway, but not the MAPK/Erk pathway, in EC cells after treatment with supernatants from uterine smooth muscle cells [41]. Zhao et al. reported that stimulation with exogenous SDF$1 \alpha$ could induce EC cell growth through activating PI3K/ Akt and MAPK/Erk pathways in a dose-dependent manner [42]. Previous studies have documented a direct involvement of PI3K/Akt and Erk signaling pathways in cardioprotection and chemotherapy resistance mediated by the SDF-1/CXCR4 axis [43, 44]. Zhuo's group has stated that SDF-1 increased phosphorylation of Akt and Erk $1 / 2$ in mouse lymphatic endothelial cells, when CXCR4 was blocked by its neutralizing antibody or knocked down by effective small interfering RNA (siRNA) eliminated the effect of SDF-1 on activated of Akt and Erk1/2 [45]. Similarly, these two pathways were both activated by secretions from CAFs in our study. In addition, AMD3100 could inhibit SDF-1 $\alpha$ induced Akt and Erk activation. Our findings elucidated that SDF-1 $\alpha$-induced intracellular signaling activation was a downstream effect of CXCR4. These observations were also compatible with changes in the biologic responses, such as cell growth, migration, and invasion, to CAF-conditioned media treatment or to AMD3100 pretreatment of EC cells. Therefore, one potential mechanism of CAFs promoting EC development is that SDF- $1 \alpha$ is engaged in tumorigenesis in a paracrinedependent manner.

Metastasis is an organized sequence of events beginning with the detachment of neoplastic cells from a primary tumor and their entry into the circulation, dissemination, and arrest at select organs [46]. A degradation of basement membrane is the first step toward invasion and metastasis. Type IV collagen is the main component of basement membrane, and destruction of this structural protein is favored by two MMPs, namely gelatinase A (MMP-2) and gelatinase B (MMP-9) [47]. These MMPs are known to be closely associated with the malignant potential of tumor cells. CAFs affect cancer cell invasion by both cell-cell contact and proinvasive factor secretion. CAFs are also one of the most significant contributors to MMP production [48]. Koontongkaew et al. reported that direct contact between tumor and fibroblast cells was required to activate MMP-2 and MMP-9 secretion in both tumor cells and fibroblasts. Moreover, it was demonstrated that fibroblasts seemed to be responsible for the increased MMP-2 in the coculture. In addition, fibroblast- or tumor cell-conditioned media upregulated the secretion of MMP-2 and MMP-9 in HNSCC cells. These findings indicated that the SDF-1/CXCR4 signaling pathway might cause an increase in cellular motility, as well as MMP-2 and MMP-9 activation, in autocrine- and paracrine-dependent manners [49]. However, we simply found that the SDF-1/CXCR4 axis played a role in the invasion and metastasis of EC in an autocrinedependent mode.

We investigated and clarified the clinical significance of SDF- $1 \alpha$ expression in EC. The data showed that SDF$1 \alpha$ expression was upregulated and was associated with tumor progression. In addition, patients with high SDF$1 \alpha$ expression showed significantly poorer oncologic 
outcomes than patients with negative and low expression, suggesting that SDF- $1 \alpha$ is an independent prognostic factor in EC. In contrast, no significant associations were documented between the expression of CXCR4 and the clinicopathologic characteristics of EC. Similarly, this parameter was not proved to play role in the negative prognosis with this malignancy. The number of published reports on the prognostic value of the SDF1/CXCR4 axis in EC patients is small [50]. Furthermore, the results of these studies have been inconclusive and sometimes contradictory. Mizokami et al. found reverse correlation between histological grade and the stromal expression of SDF-1 and CXCR4 in 41 EC cases [51]. Another study showed that positive SDF1 expression was associated with longer overall survival and longer recurrence-free survival in ER-negative patients [52]. However, in a recent study in 92 patients with EC, the authors revealed that higher expression of SDF-1/CXCR4 axis components was associated with worse prognosis [17]. These evidences suggest that the role of the SDF-1/CXCR4 axis in the progression of EC remains undefined. It might be these studies adopted different sets of prognostic factors and various classification systems for protein expression.

\section{Conclusions}

Taken together, our results suggest that CAFs derived from EC tissues promoted EC progression via the SDF-1/CXCR4 axis. Furthermore, SDF- $1 \alpha$ expression emerged a novel independent poor prognostic factor for predicting survival in patients with EC. Thus, suppression of the SDF-1/CXCR4 axis in a primary tumor environment might be a target for therapy in EC patients.

\section{Methods}

\section{Ethics statement}

This study was approved by the Ethics Committee of Tianjin Medical University General Hospital. Written informed consent was obtained from all participants.

\section{Isolation and culture of primary fibroblast cells/cell lines}

To isolate stromal fibroblasts, primary cancer tissues were obtained from 12 EC patients at Tianjin Medical University General Hospital (Tianjin, China). These patients had undergone hysterectomy but had not been treated with preoperative chemotherapy or radiotherapy. Ten NE tissues were obtained from women undergoing surgery to remove their uteruses because of leiomyomas. The tissues were divided into two parts for histopathological diagnosis and isolation of stromal fibroblasts. The EC tissues used for isolation of stromal fibroblasts were diagnosed as endometrioid adenocarcinomas. The fresh tissues were transported to the laboratory in media consisting of DMEM/F12 (Gibco, USA) supplemented with $10 \%$ fetal bovine serum (FBS) (Gibco, USA) and $1 \%$ penicillin/streptomycin (Life Technologies, USA). The tissues were minced to the size of $1 \mathrm{~mm}^{3}$ and then were digested with collagenase I ( $2 \mathrm{mg} / \mathrm{ml}$; Sigma, USA), collagenase II $(2 \mathrm{mg} / \mathrm{ml}$; Sigma, USA), and hyaluronidase $(50 \mu \mathrm{g} / \mathrm{ml}$; Sigma, USA) in DMEM/F12, using a rotator for approximately $45 \mathrm{~min}$ at $37^{\circ} \mathrm{C}$. Post-digestion, the tissues were washed and cultured in DMEM/F12 media supplemented with $10 \% \mathrm{FBS}$ and $1 \%$ penicillin/streptomycin at $37^{\circ} \mathrm{C}$. The cultures were maintained by media changes every $72 \mathrm{~h}$, and subculture was performed after the cultures reached confluency. After two to three passages, a unique homogeneity of stromal fibroblasts was formed. All the stromal fibroblasts used in the experiments were at less than 10 passages, to maintain the closest phenotype to the primary tissues. The human EC cell lines ECC-1 (CRL-2923) and HEC-1B (HTB 112) were purchased from American Type Culture Collection (Bethesda, MD, USA) and were cultured in media according to manufacturers' protocols.

\section{Identification of fibroblast cells}

Primary cultured fibroblasts from human EC and human NE were also confirmed by immunocytochemistry using rabbit anti-FSP-1 polyclonal antibody (1:300; Abcam, UK), rabbit anti-FAP polyclonal antibody (1:500; Abcam, UK), mouse anti- $\alpha$-SMA monoclonal antibody (1:300; Sigma, USA), rabbit anti-CK monoclonal antibody (1:500; Abcam, UK), rabbit anti-vimentin polyclonal antibody (1:400; Abcam, UK), and rabbit anti-CD31 polyclonal antibody (1:200; Abcam, United Kingdom). The cell seed sections were then treated with $0.3 \%$ hydrogen peroxide $\left(\mathrm{H}_{2} \mathrm{O}_{2}\right)$ in water for 10 min to quench any endogenous peroxidase activity within the tissue, and the nonspecific binding sites were blocked with $0.5 \%$ bovine serum albumin for $10 \mathrm{~min}$ at room temperature. Next, the sections were incubated for $45 \mathrm{~min}$ in the presence of the primary antibody, and then the slides were washed in phosphate-buffered saline (PBS) containing $0.1 \%$ Tween 20 (PBS/Tween) for $15 \mathrm{~min}$, with the solution changed three times before the application of the secondary biotinylated antibody. The slides were incubated with the secondary antibody for $30 \mathrm{~min}$ at room temperature before being washed for $15 \mathrm{~min}$ in PBS/ Tween, which was changed three times. The sections were then incubated for $15 \mathrm{~min}$ with an avidinbiotinylated horseradish peroxidase complex, and the reaction was visualized using $0.02 \% 3,3^{\prime}$-diaminobenzidine tetrahydrochloride as a chromogen in a Tris- $\mathrm{HCl}$ buffer, at $\mathrm{pH}$ 7.6, containing $0.03 \% \mathrm{H}_{2} \mathrm{O}_{2}$. Hematoxylin was used to counterstain the nuclei. 


\section{Preparation of conditioned media}

$\mathrm{CAFs} / \mathrm{NFs}$ were seeded and cultured in complete media for $24 \mathrm{~h}$, before being cultured in media with serum-free DMEM/F12 for the subsequent $72 \mathrm{~h}$. Conditioned medium was collected and centrifuged at $1000 \times g$ at $4{ }^{\circ} \mathrm{C}$ for $15 \mathrm{~min}$, and the supernatant was concentrated with Centricon YM3 filters (Milipore). The protein in the concentrated media was quantified using Bradford assay (Biorad, CA, USA).

\section{ELISA assay}

CAFs or NFs were seeded on six-well plates at a density of $1.5 \times 10^{5}$ cells in DMEM/F12 with $10 \%$ FBS. After $12 \mathrm{~h}$ of incubation, the media was changed to $500 \mu \mathrm{l}$ of serum-free DMEM/F12, followed by incubation for 24 , 48 , and $72 \mathrm{~h}$. The conditioned media was detected using ELISA kits, according to the manufcturers' protocol.

\section{Coculture and cell proliferation assay}

A total of $1.5 \times 10^{3} \mathrm{NFs}$ or CAFs were mixed with $4.5 \times$ $10^{3}$ HEC-1B cells or ECC- 1 cells and were seeded in complete media in 96 -well plates. At $24 \mathrm{~h}$ post-seeding, the cells were treated with serum-free media, AMD3100 (Sigma, USA) was added to cells at varying concentrations $(0,200,500 \mathrm{ng} / \mathrm{ml})$. Serum-free DMEM/F12 was added to control wells. Cell growth was analyzed at 24, 48, 72, and $96 \mathrm{~h}$ with the MTT reagent (Promega) added $4 \mathrm{~h}$ before performing spectrophotometric reading, according to the manufacturer's directions.

\section{Cell migration and invasion assays}

Cell invasive and migrative abilities were determined using transwell chambers coated with or without extracellular matrix gel (BD Biosciences, USA). A total of $1 \times$ $10^{5}$ cells/well were seeded on the upper inserts with 8$\mu \mathrm{m}$ pores (BD Biosciences, USA) and were cultured with serum-free media. In the lower chamber, $1 \times 10^{5} \mathrm{NFs}$ or CAFs in $500 \mu \mathrm{l}$ of serum-free media were planted. In the control group, there were only $500 \mu \mathrm{l}$ of serum-free media without fibroblasts in the lower chamber. Furthermore, various concentrations of AMD3100 were added to the lower wells. After $24 \mathrm{~h}$ of incubation, the cells on the upper surface of the filters were removed; the filters were fixed with $4 \%$ paraformaldehyde for $15 \mathrm{~min}$ and were stained with crystal violet stain for 30 min (Sigma, USA). The invasive and migrative activity was quantified by counting the number of transpassed cells in five random regions (magnification, $\times 200$ ) by two independent observers who were blinded to the data. Migration and invasion assays were run in triplicate, and the data were expressed as the average number of cells per random area.

\section{Nude mice xenograft assays}

All of the experimental animal procedures were approved by the Animal Care and Use Committee of Tianjin Medical University. Four-week-old female athymic nude mice were maintained in individually ventilated caging systems in groups of five. Established stable cells $\left(6 \times 10^{6} \mathrm{NFs}\right.$ or CAFs mixed with $2 \times 10^{6}$ HEC-1B cells $)$ were injected subcutaneously into the right flank of each mouse. Tumor growth was monitored at 5-day intervals by measuring the length and width of the tumor with calipers and calculating the tumor volume based on the following formula: volume $=0.5 \mathrm{LW}^{2}$. The mice were sacrificed, and the tumors were harvested and measured.

\section{Western blot analysis}

HEC-1B cells were seeded at $1 \times 10^{4}$ cells/well in sixwell plates in complete media. At $24 \mathrm{~h}$ post-seeding, the cells were treated with NF-conditioned media, CAF-conditioned media, and/or AMD3100 (200 or $500 \mathrm{ng} / \mathrm{ml}$ ) for $1 \mathrm{~h}$. Cell lysates or immunoprecipitates from cell lysates were subjected to SDS-PAGE and were transferred to polyvinylidene fluoride membranes. The membranes were incubated with the following primary antibodies: rabbit anti-human Akt, phospho-Akt, Erk, phospho-Erk, and GAPDH (Cell Signaling Technology, USA), followed by horseradish peroxidase-conjugated secondary antibody. The immunoreactive polypeptides were visualized using a chemiluminescent substrate (GE Life sciences).

\section{Zymography}

Conditioned media, standardized for cell numbers, were mixed with equal volumes of nonreducing sample buffer and were resolved on $10 \%$ Novex Zymogram gels containing $0.1 \%$ gelatin (Sigma, USA). Renaturation and detection were performed according to the manufacturer's instructions. Clear bands corresponding to gelatinolytic activity were measured by densitometry.

\section{Patients and samples}

All of the cases examined in this study were obtained from surgically removed tissues of inpatients in Tianjin Medical University General Hospital (Tianjin, China) from 2000 to 2012. The patients were confirmed by histopathology, and none of them underwent radiotherapy or chemotherapy prior to surgery. A total of $348 \mathrm{pa}-$ tients were approached. Controls were selected from women who presented for routine examination in the Department of Regular Physical Examination Center or for uterine prolapse, cystocele, or urethrocele. Among these cases, 202 patients had EC, 26 patients had HE, 33 patients had AHE, and 87 patients had NE. The histological type and grade of the primary tumors were determined by two independent pathologists based on a 
modified WHO classification system, whereas EC staging was performed based on a modified 2009 FIGO staging system.

\section{Tissue microarray}

All of the tissues for tissue microarray were obtained from formalin-fixed, paraffin-embedded tissue blocks. All of the cases were histopathologically re-evaluated and their tumor content verified on hematoxylin-eosinstained slides. Representative areas of tumor and normal tissue were selected to be cored. The tissue microarray was designed and constructed using MTA Booster and TMA Designer. The sample spots were designed to be $1.5 \mathrm{~mm}$ in diameter and to range in length from 2.0 to $5.0 \mathrm{~mm}$, depending on the depth of tissue in the donor block. A total of 48 such cylindrical cores were precisely arrayed in one recipient block.

\section{Immunohistochemistry}

The streptavidin-peroxidase-biotin immunohistochemical staining method was used to study the expression of SDF- $1 \alpha$ and CXCR4 in tissue microarray samples. Briefly, paraffin-embedded specimens were cut into 4$\mu \mathrm{m}$ sections and were baked at $60{ }^{\circ} \mathrm{C}$ for $1 \mathrm{~h}$. Endogenous peroxidase activity was quenched by incubation in $3 \%$ hydrogen peroxide/methanol buffer for $30 \mathrm{~min}$. The sections were incubated in rabbit anti-SDF- $1 \alpha$ polyclonal antibody (1:200; Abcam, UK) or rabbit anti-CXCR4 polyclonal antibody (1:400; Abcam, UK) overnight at $4{ }^{\circ} \mathrm{C}$ in humidified chambers. The following day, the sections were washed three times in PBS and were incubated in a peroxidase-conjugated goat anti-rabbit IgG antibody, which came from the streptavidin-peroxidase-biotin reagent kit, for $30 \mathrm{~min}$ at $37^{\circ} \mathrm{C}$. After being washed in PBS, the tissue sections were stained with diaminobenzidine, counterstained with hematoxylin, and then examined under a light microscope. As negative controls, tissue sections were processed as described above, except that they were incubated overnight at $4{ }^{\circ} \mathrm{C}$ in blocking solution with PBS.

\section{Scoring of immunohistochemical staining}

SDF-1 $\alpha$ and CXCR4 staining was scored based on the percentage and the intensity of positively stained cells. The five score categories for positive staining percentage were as follows: 0 , no positive cells; $1,25 \%$ or fewer positive cells; 2,26 to $50 \%$ positive cells; 3,51 to $75 \%$ positive cells; and $4,76 \%$ or more positive cells. The four score categories for staining intensity were as follows: 0 , no intensity; 1 , weak intensity; 2 , moderate intensity; and 3 , strong intensity. SDF- $1 \alpha$ and CXCR4 expression was determined by adding the positive staining percentage score to the intensity score: 0 , negative expression; $\leq 4$, low expression; and $>4$, high expression.
The staining was determined independently by two pathologists, who were blinded to the patients' clinicopathologic information.

\section{Statistical analysis}

Group comparisons of categorical variables were performed using the $\chi^{2}$ test. Comparisons of average means were performed with Student's two-tailed $t$ test or one-way ANOVA. Cancer-specific survival was defined from the date of surgery to the date of death from EC. Survival curves were plotted using the KaplanMeier method and were analyzed using the log-rank test. A Cox proportional hazards model was created to identify prognostic factors for survival. $P<0.05$ was considered to be statistically significant. All of the statistical analyses were conducted using SPSS statistical software (SPSS Inc., Chicago, IL, USA), version 14.0.

\section{Abbreviations \\ AHE: atypical hyperplastic endometrium; CAFs: cancer-associated fibroblasts; CK: cytokeratin; CSF-1: colony stimulating factor-1; CXCR4: chemokine receptor 4; EC: endometrial cancer; FAP: fibroblast-activating protein; FBS: fetal bovine serum; FSP-1: fibroblast-specific protein-1; HE: hyperplastic endometrium; IL-1: interleukin-1; MCP-1: macrophage chemoattractant protein-1; MIF: migration inhibitory factor; MMP: matrix metalloproteinases; NE: normal endometrium; NFs: normal fibroblasts; PBS: phosphate-buffered saline; SDF-1a: stromal cell-derived factor-1alpha; $a-S M A$ : alpha-smooth muscle actin.}

\section{Competing interests}

The authors declare that they have no competing interests.

\section{Authors' contributions}

FT and WYT performed almost all the experimental work. YMW and YFZ participated in the experiments and analyzed data. FG and CG investigated patients and performed the experiment. JZ designed and performed the animal experiment. FXX conceived the study and participated in its design and coordination. The manuscript was written by FT. All authors read and approved the final manuscript.

\section{Acknowledgements}

This study was supported by the Natural Science Foundation of China (no. 81272863 and 81572568), the Natural Science Fund of Tianjin Municipal Science and Technology Commission, China (no. 12JCYBJC17900), the Science and Technology Fund of Tianjin Municipal Health Bureau, China (no. 2011KZ110), and the Incubation Fund of Tianjin Medical University General Hospital, China (no. 2015022). The authors thank the Department of Neurosurgery, Laboratory of Neuro-Oncology, Tianjin Neurological Institute, the Key Laboratory of Post-trauma Neuro-repair and Regeneration in the Central Nervous System, Ministry of Education, and the Tianjin Key Laboratory of Injuries, Variations and Regeneration of Nervous System, Tianjin Medical University General Hospital for their technical assistance.

\section{Received: 10 October 2015 Accepted: 30 December 2015

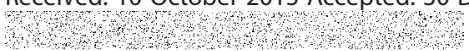

References

1. Siegel R, Ma J, Zou Z, Jemal A. Cancer statistics. CA Cancer J Clin. 2014;64(1):9-29.

2. von Gruenigen VE, Waggoner SE, Frasure HE, Kavanagh MB, Janata JW, Rose PG, et al. Lifestyle challenges in endometrial cancer survivorship. Obstet Gynecol. 2011;117(1):93-100.

3. Orimo A, Tomioka Y, Shimizu Y, Sato M, Oigawa S, Kamata K, et al. Cancerassociated myofibroblasts possess various factors to promote endometrial tumor progression. Clin Cancer Res. 2001;7(10):3097-105.

4. Kalluri R, Zeisberg M. Fibroblasts in cancer. Nat Rev Cancer. 2006;6(5):392-401. 
5. Olumi AF, Grossfeld GD, Hayward SW, Carroll PR, Tlsty TD, Cunha GR. Carcinoma-associated fibroblasts direct tumor progression of initiated human prostatic epithelium. Cancer Res. 1999;59(19):5002-11.

6. Sun Z, Wang S, Zhao RC. The roles of mesenchymal stem cells in tumor inflammatory microenvironment. J Hematol Oncol. 2014;7:14.

7. Lou G, Song X, Yang F, Wu S, Wang J, Chen Z, et al. Exosomes derived from miR-122-modified adipose tissue-derived MSCs increase chemosensitivity of hepatocellular carcinoma. J Hematol Oncol. 2015;8(1):122.

8. Bruzzese F, Hagglof C, Leone A, Sjoberg E, Roca MS, Kiflemariam S, et al. Local and systemic protumorigenic effects of cancer-associated fibroblastderived GDF15. Cancer Res. 2014;74(13):3408-17.

9. Cao H, Eppinga RD, Razidlo GL, Krueger EW, Chen J, Qiang L, et al. Stromal fibroblasts facilitate cancer cell invasion by a novel invadopodiaindependent matrix degradation process. Oncogene. 2015. doi:10.1038/onc. 2015.163. [Epub ahead of print].

10. He XJ, Tao HQ, Hu ZM, Ma YY, Xu J, Wang HJ, et al. Expression of galectin-1 in carcinoma-associated fibroblasts promotes gastric cancer cell invasion through upregulation of integrin beta1. Cancer Sci. 2014;105(11):1402-10.

11. Yu Y, Xiao CH, Tan LD, Wang QS, Li XQ, Feng YM. Cancer-associated fibroblasts induce epithelial-mesenchymal transition of breast cancer cells through paracrine TGF-beta signalling. Br J Cancer. 2014;110(3):724-32

12. Orimo A, Gupta PB, Sgroi DC, Arenzana-Seisdedos F, Delaunay T, Naeem R, et al. Stromal fibroblasts present in invasive human breast carcinomas promote tumor growth and angiogenesis through elevated SDF-1/CXCL12 secretion. Cell. 2005;121(3):335-48.

13. Augsten M. Cancer-associated fibroblasts as another polarized cell type of the tumor microenvironment. Front Oncol. 2014;4:62.

14. Lee HJ, Lee K, Lee DG, Bae KH, Kim JS, Liang ZL, et al. Chemokine (C-X-C motif) ligand 12 is associated with gallbladder carcinoma progression and is a novel independent poor prognostic factor. Clin Cancer Res. 2012;18(12):3270-80

15. Lippitz BE. Cytokine patterns in patients with cancer: a systematic review. Lancet Oncol. 2013;14(6):e218-28.

16. Domanska UM, Kruizinga RC, Nagengast WB, Timmer-Bosscha H, Huls G, de Vries EG, et al. A review on CXCR4/CXCL12 axis in oncology: no place to hide. Eur J Cancer. 2013:49(1):219-30.

17. Walentowicz-Sadlecka M, Sadlecki P, Bodnar M, Marszalek A, Walentowicz P, Sokup A, et al. Stromal derived factor-1 (SDF-1) and its receptors CXCR4 and CXCR7 in endometrial cancer patients. PLoS One. 2014;9(1):e84629.

18. Sugihara H, Ishimoto T, Yasuda T, Izumi D, Eto K, Sawayama H, et al. Cancerassociated fibroblast-derived CXCL12 causes tumor progression in adenocarcinoma of the esophagogastric junction. Med Oncol. 2015;32(6):618.

19. Izumi D, Ishimoto T, Miyake K, Sugihara H, Eto K, Sawayama H, et al. CXCL12/CXCR4 Activation by cancer-associated fibroblasts promotes integrin ss1 clustering and invasiveness in gastric cancer. Int J Cancer. 2015. doi:10.1002/ijc.29864. [Epub ahead of print].

20. Feig C, Jones JO, Kraman M, Wells RJ, Deonarine A, Chan DS, et al. Targeting CXCL12 from FAP-expressing carcinoma-associated fibroblasts synergizes with anti-PD-L1 immunotherapy in pancreatic cancer. Proc Natl Acad Sci U S A. 2013;110(50):20212-7.

21. Yoon Y, Liang Z, Zhang X, Choe M, Zhu A, Cho HT, et al. CXC chemokine receptor-4 antagonist blocks both growth of primary tumor and metastasis of head and neck cancer in xenograft mouse models. Cancer Res. 2007;67(15):7518-24

22. Harvey JR, Mellor P, Eldaly H, Lennard TW, Kirby JA, Ali S. Inhibition of CXCR4-mediated breast cancer metastasis: a potential role for heparinoids? Clin Cancer Res. 2007;13(5):1562-70.

23. Lapteva N, Yang AG, Sanders DE, Strube RW, Chen SY. CXCR4 knockdown by small interfering RNA abrogates breast tumor growth in vivo. Cancer Gene Ther. 2005;12(1):84-9.

24. Jia CC, Wang TT, Liu W, Fu BS, Hua X, Wang GY, et al. Cancer-associated fibroblasts from hepatocellular carcinoma promote malignant cell proliferation by HGF secretion. PLoS One. 2013;8(5):e63243.

25. Subramaniam KS, Tham ST, Mohamed Z, Woo YL, Mat Adenan NA, Chung I. Cancer-associated fibroblasts promote proliferation of endometrial cancer cells. PLoS One. 2013;8(7):e68923.

26. Cai J, Tang H, Xu L, Wang X, Yang C, Ruan S, et al. Fibroblasts in omentum activated by tumor cells promote ovarian cancer growth, adhesion and invasiveness. Carcinogenesis. 2012;33(1):20-9.

27. Li H, Zhang J, Chen SW, Liu LL, Li L, Gao F, et al. Cancer-associated fibroblasts provide a suitable microenvironment for tumor development and progression in oral tongue squamous cancer. J Transl Med. 2015;13:198.

28. Verdelli C, Avagliano L, Creo P, Guarnieri V, Scillitani A, Vicentini L, et al. Tumour-associated fibroblasts contribute to neoangiogenesis in human parathyroid neoplasia. Endocr Relat Cancer. 2015;22(1):87-98.

29. Flaberg E, Markasz L, Petranyi G, Stuber G, Dicso F, Alchihabi N, et al. Highthroughput live-cell imaging reveals differential inhibition of tumor cell proliferation by human fibroblasts. Int J Cancer. 2011;128(12):2793-802.

30. Chang PH, Hwang-Verslues WW, Chang YC, Chen CC, Hsiao M, Jeng YM, et al. Activation of Robo1 signaling of breast cancer cells by Slit2 from stromal fibroblast restrains tumorigenesis via blocking PI3K/Akt/beta-catenin pathway. Cancer Res. 2012;72(18):4652-61.

31. Stuelten $\mathrm{CH}$, Busch II, Tang B, Flanders KC, Oshima A, Sutton E, et al. Transient tumor-fibroblast interactions increase tumor cell malignancy by a TGF-beta mediated mechanism in a mouse xenograft model of breast cancer. PLoS One. 2010;5(3):e9832.

32. Harper J, Sainson RC. Regulation of the anti-tumour immune response by cancer-associated fibroblasts. Semin Cancer Biol. 2014;25:69-77.

33. Hwang RF, Moore T, Arumugam T, Ramachandran V, Amos KD, Rivera A et al. Cancer-associated stromal fibroblasts promote pancreatic tumor progression. Cancer Res. 2008;68(3):918-26.

34. Arnold JT, Lessey BA, Seppala M, Kaufman DG. Effect of normal endometrial stroma on growth and differentiation in Ishikawa endometrial adenocarcinoma cells. Cancer Res. 2002;62(1):79-88.

35. Shi M, Zhang H, Li M, Xue J, Fu Y, Yan L, et al. Normal endometrial stromal cells regulate survival and apoptosis signaling through PI3K/AKt/Survivin pathway in endometrial adenocarcinoma cells in vitro. Gynecol Oncol. 2011; 123(2):387-92.

36. Shirozu M, Nakano T, Inazawa J, Tashiro K, Tada H, Shinohara T, et al. Structure and chromosomal localization of the human stromal cell-derived factor 1 (SDF1) gene. Genomics. 1995;28(3):495-500.

37. Bleul CC, Farzan M, Choe H, Parolin C, Clark-Lewis I, Sodroski J, et al. The lymphocyte chemoattractant SDF-1 is a ligand for LESTR/fusin and blocks HIV-1 entry. Nature. 1996;382(6594):829-33.

38. Broxmeyer HE, Orschell CM, Clapp DW, Hangoc G, Cooper S, Plett PA, et al. Rapid mobilization of murine and human hematopoietic stem and progenitor cells with AMD3100, a CXCR4 antagonist. J Exp Med. 2005;201(8):1307-18.

39. Ma M, Ye JY, Deng R, Dee CM, Chan GC. Mesenchymal stromal cells may enhance metastasis of neuroblastoma via SDF-1/CXCR4 and SDF-1/CXCR7 signaling. Cancer Lett. 2011;312(1):1-10.

40. Schmidt E, Haase M, Ziegler E, Emons G, Grundker C. Kisspeptin-10 inhibits stromal-derived factor 1-induced invasion of human endometrial cancer cells. Int J Gynecol Cancer. 2014;24(2):210-7.

41. Tsukamoto H, Shibata K, Kajiyama H, Terauchi M, Nawa A, Kikkawa F. Uterine smooth muscle cells increase invasive ability of endometrial carcinoma cells through tumor-stromal interaction. Clin Exp Metastasis. 2007;24(6):423-9.

42. Zhao D, Li XP, Gao M, Zhao C, Wang JL, Wei LH. Stromal cell-derived factor 1alpha stimulates human endometrial carcinoma cell growth through the activation of both extracellular signal-regulated kinase 1/2 and Akt. Gynecol Oncol. 2006;103(3):932-7.

43. Singh S, Srivastava SK, Bhardwaj A, Owen LB, Singh AP. CXCL12-CXCR4 signalling axis confers gemcitabine resistance to pancreatic cancer cells: a novel target for therapy. Br J Cancer. 2010;103(11):1671-9.

44. Hu X, Dai S, Wu WJ, Tan W, Zhu X, Mu J, et al. Stromal cell derived factor-1 alpha confers protection against myocardial ischemia/reperfusion injury: role of the cardiac stromal cell derived factor-1 alpha CXCR4 axis. Circulation. 2007;116(6):654-63.

45. Zhuo W, Jia L, Song N, Lu XA, Ding Y, Wang X, et al. The CXCL12-CXCR4 chemokine pathway: a novel axis regulates lymphangiogenesis. Clin Cancer Res. 2012;18(19):5387-98.

46. Noel A, Gutierrez-Fernandez A, Sounni NE, Behrendt N, Maquoi E, Lund IK, et al. New and paradoxical roles of matrix metalloproteinases in the tumor microenvironment. Front Pharmacol. 2012;3:140.

47. Bjorklund $M$, Koivunen E. Gelatinase-mediated migration and invasion of cancer cells. Biochim Biophys Acta. 2005;1755(1):37-69.

48. Fullar A, Kovalszky I, Bitsche M, Romani A, Schartinger VH, Sprinzl GM, et al. Tumor cell and carcinoma-associated fibroblast interaction regulates matrix metalloproteinases and their inhibitors in oral squamous cell carcinoma. Exp Cell Res. 2012;318(13):1517-27.

49. Koontongkaew S, Amornphimoltham P, Monthanpisut P, Saensuk T, Leelakriangsak M. Fibroblasts and extracellular matrix differently modulate 
MMP activation by primary and metastatic head and neck cancer cells. Med Oncol. 2012;29(2):690-703.

50. Smith AD, Roda D, Yap TA. Strategies for modern biomarker and drug development in oncology. J Hematol Oncol. 2014;7:70.

51. Mizokami Y, Kajiyama H, Shibata K, Ino K, Kikkawa F, Mizutani S. Stromal cellderived factor-1alpha-induced cell proliferation and its possible regulation by CD26/dipeptidyl peptidase IV in endometrial adenocarcinoma. Int J Cancer. 2004;110(5):652-9.

52. Felix AS, Stone RA, Chivukula M, Bowser R, Parwani AV, Linkov F, et al. Survival outcomes in endometrial cancer patients are associated with CXCL12 and estrogen receptor expression. Int J Cancer. 2012;131(2):E114-21.

Submit your next manuscript to BioMed Central and we will help you at every step:

- We accept pre-submission inquiries

- Our selector tool helps you to find the most relevant journal

- We provide round the clock customer support

- Convenient online submission

- Thorough peer review

- Inclusion in PubMed and all major indexing services

- Maximum visibility for your research

Submit your manuscript at www.biomedcentral.com/submit
Biomed Central 